\title{
Benign chondrolipomatous tumour of the breast
}

\author{
D. D. DHARKAR \\ J. R. KRAFT \\ M.B. B.S., D.C.P., M.D.(Path.) \\ M.D., F.C.A.P. \\ Department of Clinical Pathology and Nuclear Medicine, \\ St Joseph Hospital, Chicago, Illinois 60657 U.S.A.
}

\begin{abstract}
Summary
Cartilage associated with malignant neoplasms of breast has been known and documented for over 200 years. Benign breast tumours containing cartilage are rare. A case of such a tumour was encountered. Histologically it comprised multiple foci of mature benign cartilage in benign fibrous and adipose stroma. Other cases of similar tumours in the literature are reviewed.
\end{abstract}

\section{Introduction}

The findings of cartilage in neoplasms of breast have been reported in a number of cases and have been documented for more than 200 years (Smith and Taylor, 1969). The malignant breast tumours are the ones most commonly associated with cartilage (Allen, 1940; Curran and Dodge, 1962; Jenstrom, Lindberg and Meland, 1963; Oberman, 1965; Rottino and Howley, 1945; Smith and Taylor, 1969). The last reported case of a benign chondrolipomatous tumour of the breast was in 1977 (Kaplan and Walts, 1977). A similar case encountered by the present authors is reported.

\section{Case report}

A 39-year-old woman, para 4, was admitted to the hospital for a mass felt in the upper inner quadrant of her right breast. The size of the mass was $1 \times 2 \mathrm{~cm}$. No lymph nodes were felt. There was no history of trauma, infection, prior surgery at the site or nipple discharge. This mass had been present for 2 months and was firm, non-tender and did not appear to be fixed to underlying tissue or chest wall. No skin changes were noted. An excisional biopsy was performed.

On gross examination, the tumour was grey-white with 'gritty' areas on cut section. Microscopic examination revealed increase of the perilobular and intralobular fibrous tissue with the presence of multiple foci of orderly hyaline cartilage in fibrolipomatous tissue of the breast (Figs. 1 and 2). The mammary ducts showed minimal dilatation. No atypia was noted. For want of a better term, this condition was called 'chondroma, chondrometaplasia'.

\section{Discussion}

Malignant tumours of the breast, especially sarcomas, are frequently associated with chondromatosis; but this is a rare occurrence in benign tumours of the female breast. Kaplan and Walts (1977), reporting one such case, could find only 7 reports of benign cartilage containing tumours of the human breast in the literature, encompassing a period of 116 years, extending from the years 1860 to 1976 . The last case they quoted had been reported in 1909.

Benisch, Peison and Sarno (1976) have described a benign tumour of breast in which cartilage, fat and smooth muscle were intermixed. They called this tumour benign mesenchymoma of the breast.

Smith and Taylor (1969) discussed the occurrence of bone and cartilage in mammary tumours and described 9 benign tumours which had features of 'mixed tumours' with both cartilage as well as epithelial elements. These were benign tumours and follow-up studies confirmed their benign nature. One important difference between them and the chondrolipomatous tumour being presented here is that they had an admixture of epithelial and stromal elements as opposed to the pure cartilaginous and lipomatous (stromal) elements of the present case. Hence, these tumours presumably belong to a category of similar tumours encountered in the salivary glands (pleomorphic adenoma) and sweat glands (chondroid syringoma) (Hirsch and Helwig, 1961).

The histogenesis of cartilage in these tumours has been controversial. Metaplasia of epithelial cells has been considered as a possibility (Gonzalez-Licea, Yardley and Hartmann, 1967; McDivitt, Stewart and Berg, 1968). Allen (1940), in a study of canine carcinoma of the breast containing bone and cartilage, suggested that in that species, the cartilaginous component was derived from a direct transformation of tumour epithelium. Stromal metaplasia is favoured by most others (Jenstrom et al., 1963; Oberman, 1965; Rottino and Howley, 1945). 


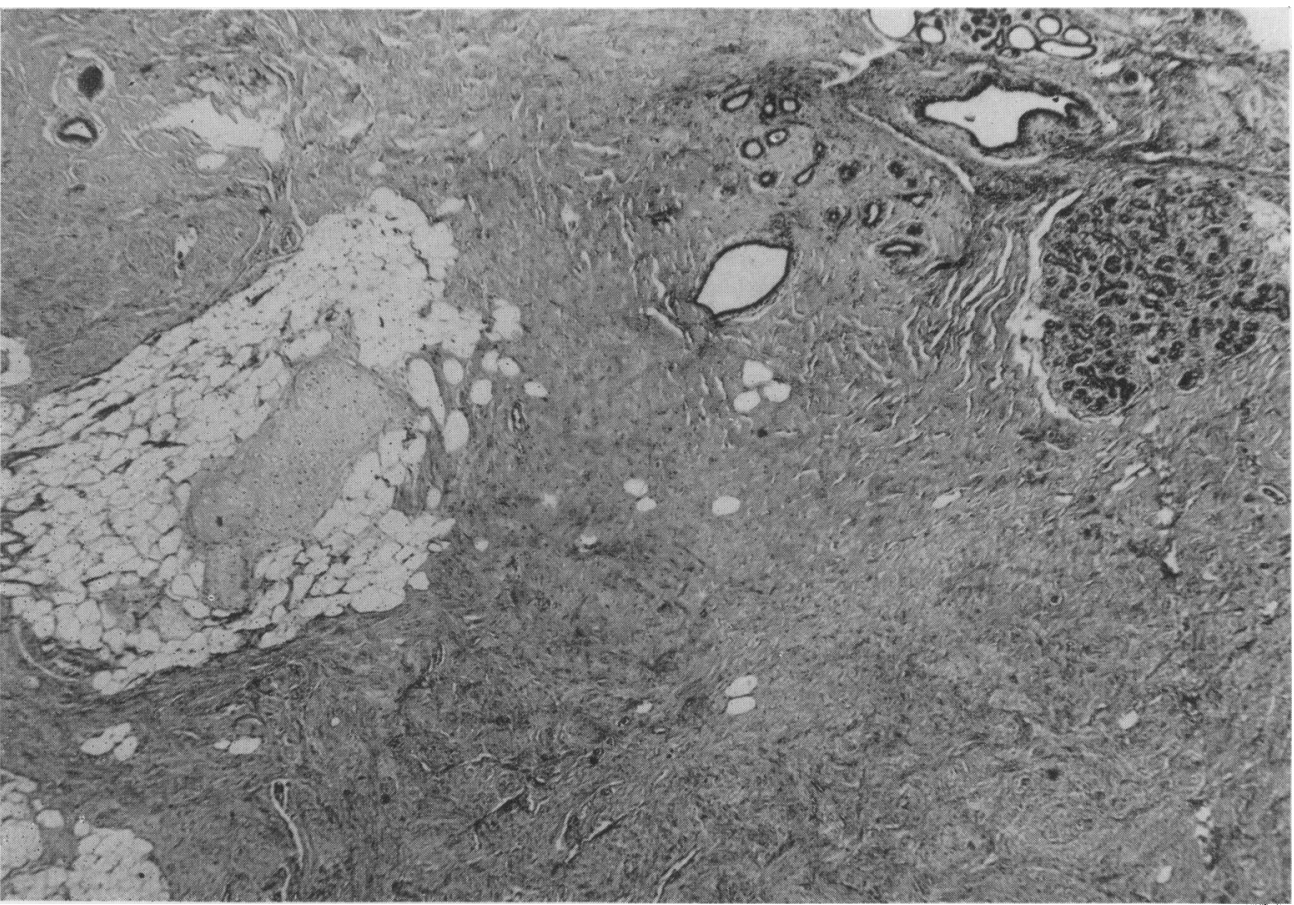

Fig. 1. Histological section through the tumour showing breast ducts, lobules, and hyaline cartilage surrounded by fibrous and adipose stroma $(\mathrm{HE}, \times 20)$.

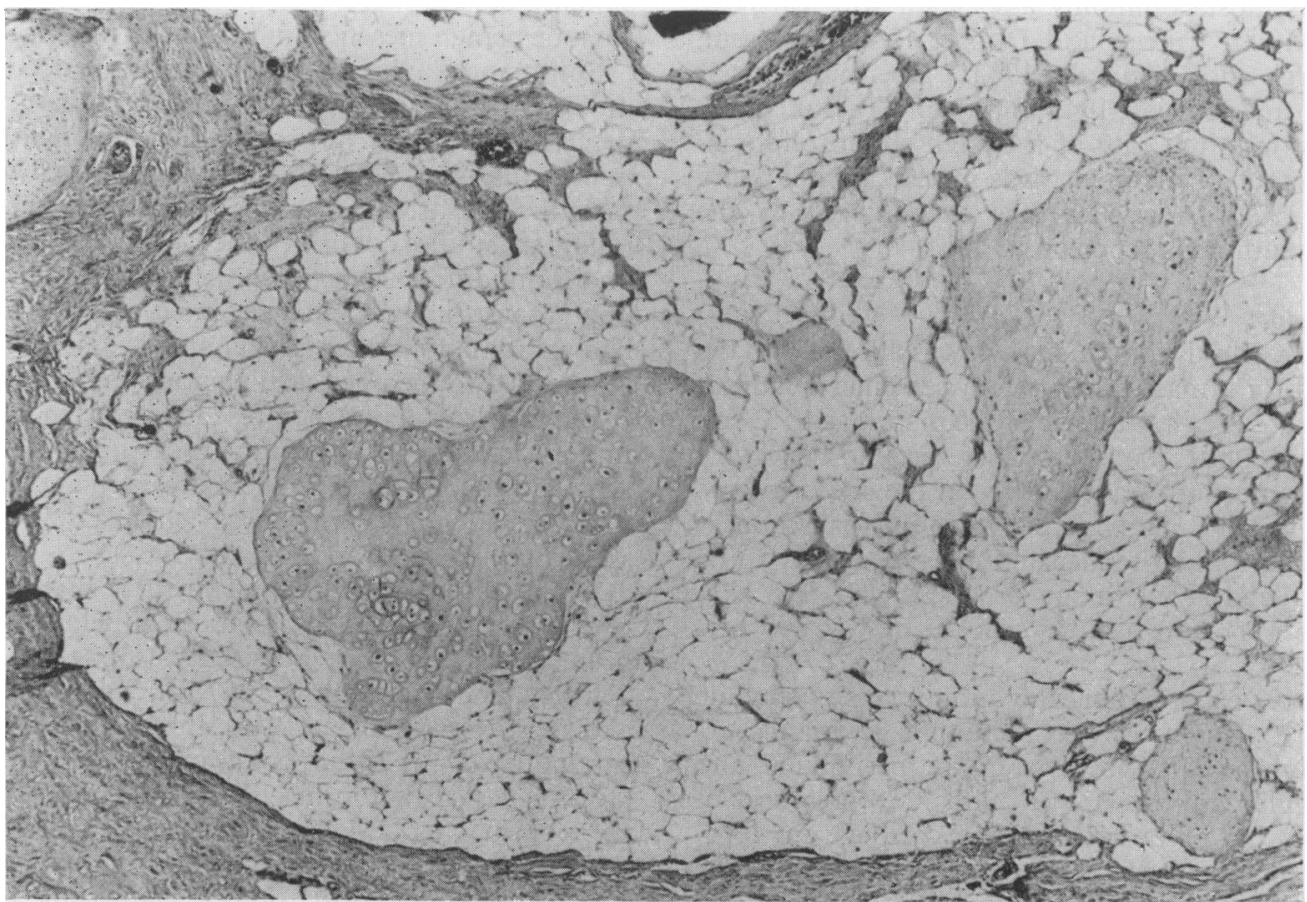

FIG. 2. Islands of cartilage in mainly adipose stroma $(\mathrm{HE}, \times 32)$. 
Another plausible theory is derivation from totipotential stromal cells (Benisch et al., 1976).

In the present case, the authors favour the derivation from stromal pleuri-potential cells. Also, as there are multiple foci of cartilaginous areas, a multicentric evolution of cartilage could be postulated.

\section{References}

Allen, A.C. (1940) So-called mixed tumor of the mammary gland of dog and man with special reference to the general problem of cartilage and bone formation. Archives of Pathology, 29, 589.

Benisch, B., Peison, P. \& Sarno, J. (1976) Benign mesenchymoma of the breast. Mount Sinai Journal of Medicine. New York, 43, 530.

Curran, R.C. \& Dodge, O.G. (1962) Sarcoma breast, with particular reference to its origin from fibroadenoma. Journal of Clinical Pathology, 15, 1.

Gonzalez-Licea, A., Yardley, J.H. \& Hartmann, W.H.
(1967) Malignant tumor of the breast with bone formation. Studies by light and electron microscopy. Cancer, 20, 1234.

Hirsch, P. \& Helwig, E.B. (1961) Chondroid syringoma. Archives of Dermatology, 84, 835.

Jenstrom, P., Lindberg, A.L. \& Meland, D.N. (1963) Osteogenic sarcoma of the mammary gland. American Journal of Clinical Pathology, 40, 521.

Kaplan, L. \& Walts, A.E. (1977) Benign chondrolipomatous tumor of the human female breast. Archives of Pathology. Chicago, 101, 149.

McDivitt, R.W., Stewart, J.W. \& Berg, J.W. (1968) Tumors of the Breast. Second series, fascicle 2, p. 94. Armed Forces Institute of Pathology, Washington, D.C.

Oberman, H.A. (1965) Sarcomas of the breast. Cancer, 18, 1233.

Rottino, A. \& Howley, C.P. (1945) Osteoid carcinoma of the breast, a complication of fibroadenoma. Archives of Pathology, 40, 44.

SMITH, B.H. \& TAYLOR, H.B. (1969) The occurrence of bone and cartilage in mammary tumors. American Journal of Pathology, 51, 610. 